\title{
International Issues: A guide to US academic global health programs in neurology
}

Rohini D. Samudralwar, MD, Adeline Goss, MD, Kathryn Rimmer, MD, Kara Shetler, MD, Allison Navis, MD, Omar K. Siddiqi, MD, MPH, Jerome H. Chin, MD, PhD, MPH, and Kiran T. Thakur, MD

Neurology ${ }^{\circledR}$ 2018;90:662-665. doi:10.1212/WNL.0000000000005267

\author{
Correspondence \\ Dr. Thakur \\ ktt2115@cumc.columbia. \\ edu
}

Global health programs advocate for a better understanding of health disparities, often prompting medical trainees to practice medicine in an international setting. The relevance of global health electives in neurology is highlighted by the increasing burden of neurologic diseases in low- and middle-income countries (LMICs), representing $84 \%$ of the world's population. ${ }^{1,2}$ Cerebrovascular disease is the second leading cause of morbidity and mortality worldwide, and dementia, meningitis, migraine, and epilepsy are in the top 50 factors in disability-adjusted life years. Neurologists therefore play a key role in global health, caring for patients with acute neurologic disorders and neurologic sequelae of both noncommunicable and communicable diseases. Despite this, there are only 0.03 to 1.09 neurologists per 100,000 people in LMICs, with large inequalities in access to care, compared to 4.75 per 100,000 population in high-income countries. ${ }^{3}$ Through developing collaborative relationships and a cross-cultural exchange of knowledge, US neurology trainees can play a role in addressing these disparities in neurologic care.

Many US neurology residency programs have developed global health programs that can provide a mutually beneficial exchange of resources and training programs between partner institutions in one or more LMICs. Federal and foundation funding has increased over the last decade, extending support to subspecialties in neurology including movement disorders, neuroinfectious disease, epilepsy, and stroke. ${ }^{4}$ For trainees, these placements can expand knowledge of neurologic diseases, improve clinical skills, and help develop an appreciation of public health, cultural, and socioeconomic issues affecting the population of the partner country. ${ }^{5}$ The host institution is supported through clinical teaching of local health care personnel, patient care, and research.

The Global Health Section of the American Academy of Neurology (AAN) has established a network of neurologists within the AAN to advance international collaborations and to foster global health interest among neurology trainees in the United States and other countries. The Section includes 443 members, and is one of the fastest growing sections of the AAN particularly among trainees. One critical goal is to connect US neurology trainees with clinical and research opportunities in LMICs, and to develop mutually beneficial exchanges that can ultimately improve neurologic care in resource-limited settings. To facilitate this, the Global Health Section of the AAN has compiled a list of available global neurology electives for interested trainees (appendix e-1, links.lww.com/WNL/A326). Information gathered for appendix e-1 was through a request via email and discussion through Synapse AAN Online Communities to members of the AAN global health section. While this is not a complete list, it provides a sample of programs, which have been made available through the AAN. This article offers predeparture, funding, and postdeparture advice to ensure a meaningful elective rotation focused on mutual enrichment of home and host institutions.

\footnotetext{
From the Department of Neurology (R.D.S.), Washington University in St. Louis, MO; Department of Neurology (A.G.), University of California, San Francisco Medical Center; Department of Neurology (K.R., K.S., K.T.T.), Columbia University Medical Center, New York; Department of Neurology (A.N.), Icahn School of Medicine Mount Sinai, New York, NY; Global Neurology Program, Department of Neurology (O.K.S.), and Center for Virology and Vaccine Research, Department of Neurology (O.K.S.), Beth Israel Deaconess Medical Center, Harvard Medical School, Boston, MA; Department of Internal Medicine (O.K.S.), University of Zambia School of Medicine, Lusaka, Zambia; and Department of Neurology (J.H.C.), NYU Langone Health, New York, NY.

Go to Neurology.org/N for full disclosures. Funding information and disclosures deemed relevant by the authors, if any, are provided at the end of the article.
} 


\section{Selecting a program}

Programs in global neurology vary in focus, duration, and trainee level. In selecting a program, trainees often choose between a clinical or research focus. This decision will help narrow the search for programs and guide further logistical planning. It is important to note that many clinically oriented programs may still encourage a small-scale project, such as a prospective case series or evaluation of practice patterns or resources. Some may also incorporate training of local health care providers including nurses and physician extenders.

Region and language barriers can also play a role in decisionmaking. The importance of language skills depends on the duration of the trip and the type of project the trainee intends to pursue. For any in-depth research or clinical experience, trainees should strongly consider working in a location where they have familiarity with the local language. This is important both to maximize their productivity and to minimize burden on the host institution.

Once a trainee identifies the preferred focus and geographic region, he or she can begin to search for specific programs. We offer the attached appendix e-1 (links.lww.com/WNL/A326) as a starting point for medical students, residents, and fellows, as well as the figure as an example timeline in preparation for a global health rotation. Many programs are geared towards senior neurology residents, while others are available to trainees across all levels. This list is not comprehensive, and we encourage trainees to explore advertised and unadvertised opportunities at their home institutions, as well as those with the $\mathrm{NIH}$ and nongovernmental organizations.

\section{Predeparture planning}

Early planning is the key to a successful global health rotation. This is particularly true for residents and fellows. Residents may find it difficult to schedule an international elective, in part because the Accreditation Council for Graduate Medical Education requires participation in a continuity clinic throughout training. ${ }^{6}$ Fellows have a similar challenge scheduling around duties. It is important to discuss the timing of a global health project with one's program director, administrative director, and chief resident to schedule clinic-free and call-free electives. More than a year of planning may be necessary. Programmatic approval as well as compliance with ACGME takes a significant amount of time, and trainees should be in close communication with their administrative director of education to facilitate necessary paperwork for approvals 1 year prior to departure. Trainees meeting challenges may benefit from structuring their global health work as part of their protected research time or as a grant-funded project; this may ensure dedicated time to a global health program without missing local resident or fellow duties.

Identifying mentors at home and host sites is another key step in planning a meaningful international elective. At home institutions, US trainees should seek out at least one mentor with substantial global health experience who can provide advice on rotation structure, logistics, and cross-cultural issues. Ideally, this mentor will have an established relationship with the partner institution. Trainees should also identify a neurologist at their home institution (not necessarily the same individual) who shares their clinical or research interests and can help develop the specifics of the elective. In the programs listed in appendix e-1 (links.lww.com/WNL/ A326), many have trained neurologists or other physicians designated to oversee activities in the host countries. In addition, a host site coordinator who can assist with the required documentation for medical licensing (if required), malpractice, housing, local transportation, and safety should be identified. A faculty mentor at the visiting institution is often required for supervision and evaluation of the trainee.

In preparation for the visit, trainees should refresh their training in cultural humility, cross-cultural communication (including working with interpreters), medical ethics, and unconscious bias. ${ }^{6}$ Many programs have required global health courses and predeparture training on one or more of these topics. Mentors can assist with orienting the trainee to specific cultural norms and geopolitical issues in the country he or she will be visiting.

\section{Travel safety and health}

For resources on travel security, the US Department of State's website has updated country-specific travel warnings and alerts. ${ }^{7}$ Updated information on country-specific travel health alerts, vaccinations, and prophylaxis is available at the Centers for Disease Control and Prevention website. ${ }^{8}$ Some vaccinations may need to be administered 4-6 weeks in advance of arrival to the host country and an appointment with a travel medicine expert is recommended at least 6 months prior to travel. Trainees should plan to bring their own antiretroviral medications for postexposure prophylaxis if not readily available in host country. A 4-week supply can be prescribed by a trainee's physician. Evacuation insurance can also be purchased in case of medical emergencies. This may be provided as a supplement to existing insurance for an additional fee or free of charge with affiliated institution.

\section{Travel documents}

It is important to have a valid passport that is not due to expire within 6 months of foreign site arrival or departure. In addition, some countries in South America, Africa, the Middle East, South East Asia, and Oceania require a visa upon entry for holders of a US passport. Country-specific visa application requirements are available at the US Department of State's website. It is recommended that at least 3-4 months be allocated for securing a passport or visa.

\section{Institutional review board}

For research projects, the process of institutional review board (IRB) approval may involve review by both US and partner institutions. Of note, some project proposals may be exempt from IRB approval, but should be confirmed through formal IRB processes. In addition, IRBs in the United States 


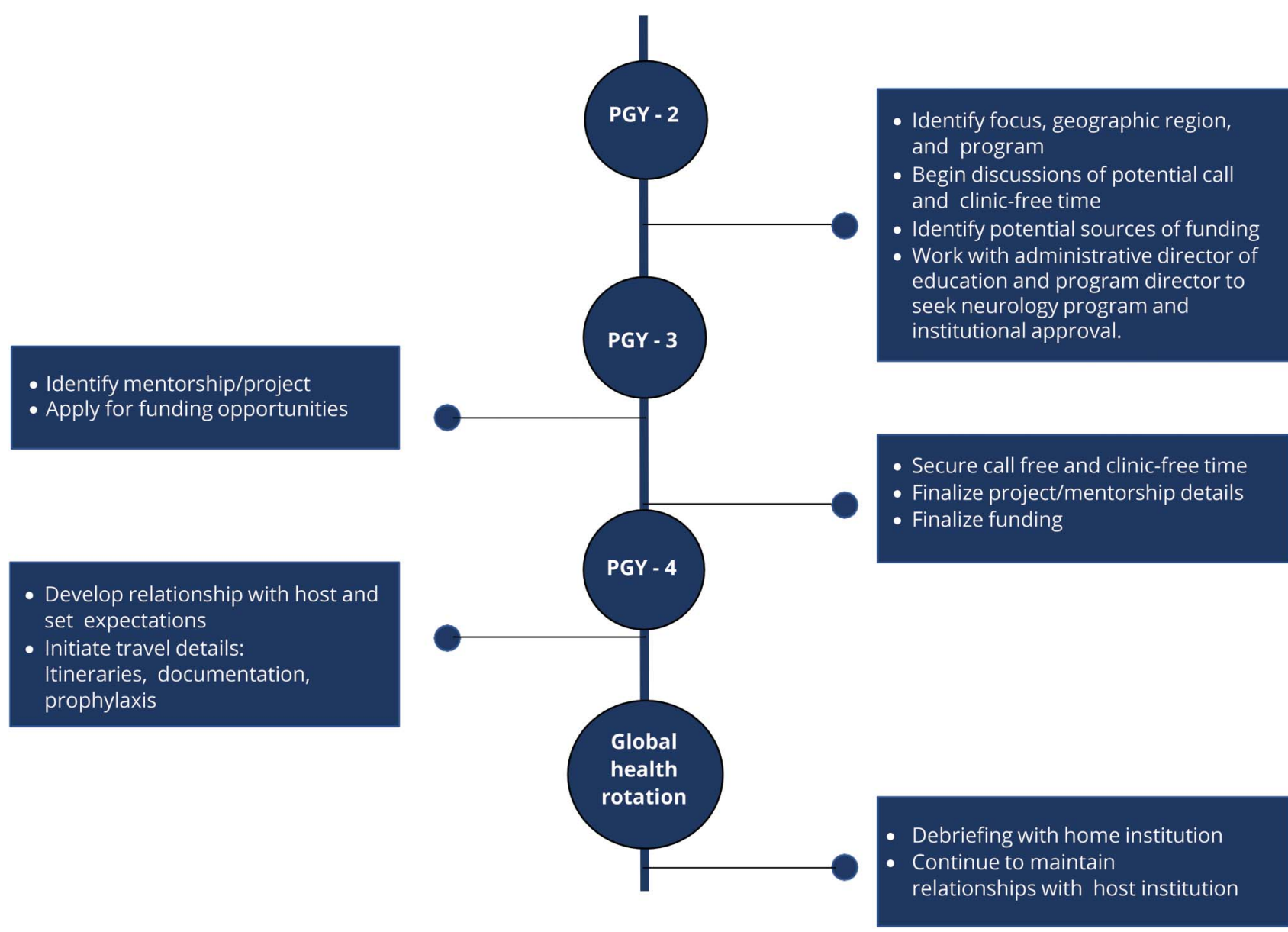

This timeline depicts an example of steps needed to successfully plan for a global health rotation as a resident. For fellows, the basic sequence of events is maintained but can be shifted for later on in training.

generally conduct reviews based on different ethical schemas (e.g., the Common Rule) than those in other countries (e.g., the Declaration of Helsinki). ${ }^{9}$ For these reasons, the researcher should contact both institutions well before departure to clarify application requirements for approval or exemption. Research mentors can provide guidance in these cases.

\section{Funding}

Estimating project expenses is a fundamental aspect of predeparture planning. Costs may include materials (e.g., laboratory equipment, clinical instruments, fuel and food for volunteer collaborators traveling to project sites) and services (e.g., translation fees, printing, data analysis) required to carry out the project. Other costs include personal expenses, such as housing, food, transportation, passport or visa fees, predeparture vaccinations, and prophylactic medications. Requirements for a national medical license and malpractice insurance vary by location and may pose additional costs. ${ }^{10}$

Many programs listed in appendix e-1 (links.lww.com/WNL/ A326) offer limited funding. Trainees should reach out to their residency program directors or medical school global health office to inquire about internal grants or scholarships for independently organized projects. If these are nonexistent or inadequate, external programs should be considered (table e-1, links.lww.com/WNL/A325). Stipulations on the allocation of funds vary by source, and the trainee should be prepared to pay for a portion of ancillary expenses with personal funds. For research projects, it may be possible to apply for grants or obtain sponsorship through a mentor. Once the project is underway, the trainee should document all expenses carefully and keep itemized receipts, as some funding sources may require these for reimbursement. Once budget estimates and funding sources are determined, the trainee will need a US bank account with reliable access to funds in the destination country. Automated teller machines or money transfer accounts such as Western Union can be useful methods to access funds internationally. Another option is to open an account at an international bank with branches in the rotation site.

\section{Telecommunications}

It is crucial to establish telecommunication as early as possible. If the trainee has a smartphone, it can be unlocked during the 
predeparture period and used to operate an international SIM card giving the trainee access to the cellular network (i.e., phone, SMS, and data) of the destination country. Alternatively, an inexpensive mobile phone and SIM card can often be purchased locally. Internet access can also be an issue and although some areas may provide wifi, this is not always dependable.

\section{Arrival and troubleshooting}

Establishing contact with the host coordinator upon arrival can address any issues with housing, transportation, or telecommunications. In addition, access to site facilities and familiarity with surroundings can ease the transition to an international environment. Throughout the course of the elective, it is imperative to designate time and maintain contact with mentors to meet the goals of a research project or clinical activity. This will also address issues early, allowing for a more successful outcome. Creating a log of patients, procedures, and experiences will provide a reference for personal education and can facilitate postdeparture debriefings with home institutions.

\section{Postdeparture debriefing}

After the trainee's elective is completed, it is important to debrief with mentors at both home and partner institutions to review the strengths, weaknesses, and future directions of the collaboration. This facilitates growth on both institutional and personal levels by translating partnerships into insight and self-improvement. Some programs may require presentations and research to be shared with the neurology department and other audiences. Regardless of a project's measurable outcomes (e.g., adequate research data collection, successful establishment of clinical programs), its legacy derives from the strengthening of institutional relationships and successful reporting back of individual experiences. Connections with the host institution should be continued through email and teleconferences to continue sharing knowledge and experiences. Ideally a trainee will be able to practice at the site not only once, but establish a longitudinal relationship. Additionally, exchange opportunities should be implemented if available.

\section{Discussion}

Global health activities offer US neurology trainees opportunities to expand their clinical and research knowledge and skills, develop an informed appreciation of global health disparities, and interact with clinicians and researchers in LMICs. The discipline of global health is evolving, and the opportunities for training abroad are likely to grow as there is increased recognition of global health disparities in neurology.

\section{Author contributions}

Dr. Samudralwar: acquisition of data, original manuscript draft, critical revision of the manuscript. Dr. Goss: original manuscript draft, critical revision of the manuscript. Dr. Rimmer: acquisition of data, original manuscript draft, finalization and verification of appendix, revision of the manuscript. Dr. Shetler: acquisition of data, original manuscript draft, finalization and verification of table, revision of the manuscript. Dr. Navis: original manuscript draft, revision of the manuscript. Dr. Siddiqi: critical revision of the manuscript. Dr. Chin: critical revision of the manuscript. Dr. Thakur: study supervision, critical revision of the manuscript.

\section{Acknowledgment}

Amy C. Lee, MD, MPH (Palo Alto Medical Foundation, Mountain View, CA) and Ana-Claire L. Meyer, MD (Senior Clinical Advisor at US Army, Medical Research and Material Command and Adjunct Assistant Professor, Yale School of Medicine, New Haven, CT) developed the original list and information of global health programs in appendix e-1 (links. lww.com/WNL/A326). Members of the Global Health Section of the AAN who provided institutional and affiliate information to assemble appendix e-1.

\section{Study funding}

No targeted funding reported.

\section{Disclosure}

The authors report no disclosures relevant to the manuscript. Go to Neurology.org/N for full disclosures.

\section{References}

1. Group GBDNDC. Global, regional, and national burden of neurological disorders during 1990-2015: a systematic analysis for the Global Burden of Disease Study 2015. Lancet Neurol 2017;16:877-897.

2. World Bank Open Data [Internet]. 2017. Available at: data.worldbank.org/. Accessed October 15, 2017.

3. Atlas: Country Resources for Neurological Disorders, 2nd ed. Geneva: World Health Organization; 2017.

4. Lyons JL, Coleman ME, Engstrom JW, Mateen FJ. International electives in neurology training: a survey of US and Canadian program directors. Neurology 2014;82: 119-125.

5. Birbeck GL. Careers in global neurology. Ann Neurol 2014;75:805-809.

6. Accreditation Council for Graduate Medical Education. Neurology: program requirements and FAQs 2017 [online]. Available at: acgme.org/Specialties/ProgramRequirements-and-FAQs-and-Applications/pfcatid/37/Neurology. Accessed October $11,2017$.

7. Bureau of Consular Affairs U.S. Department of State. Travel.State.Gov 2017 [online]. Available at: travel.state.gov/content/travel/en.html. Accessed August 31, 2017.

8. Centers for Disease Control and Prevention, Office of the Associate Director for Communication of Public Affairs. Centers for Disease Control and Prevention: Travelers' health 2014 [online]. Available at: nc.cdc.gov/travel/. Accessed August 31, 2017.

9. Barchi F, Kasimatis Singleton M, Merz JF. Fostering IRB collaboration for review of international research. Am J Bioeth 2014;14:3-8.

10. Fleisher JE, Mateen FJ. Neurology goes global: opportunities in international health. Neurol Clin Pract 2014;4:239-246. 


\section{Neurology}

International Issues: A guide to US academic global health programs in neurology

Rohini D. Samudralwar, Adeline Goss, Kathryn Rimmer, et al.

Neurology 2018;90;662-665

DOI 10.1212/WNL.0000000000005267

This information is current as of April 2, 2018

\section{Updated Information \&} Services

References

Citations

Subspecialty Collections

Permissions \& Licensing

Reprints including high resolution figures, can be found at: http://n.neurology.org/content/90/14/662.full

This article cites 5 articles, 2 of which you can access for free at: http://n.neurology.org/content/90/14/662.full\#ref-list-1

This article has been cited by 1 HighWire-hosted articles: http://n.neurology.org/content/90/14/662.full\#\#otherarticles

This article, along with others on similar topics, appears in the following collection(s):

All global neurology

http://n.neurology.org/cgi/collection/all_global_neurology

Other Education

http://n.neurology.org/cgi/collection/other_education

Information about reproducing this article in parts (figures,tables) or in its entirety can be found online at:

http://www.neurology.org/about/about_the_journal\#permissions

Information about ordering reprints can be found online:

http://n.neurology.org/subscribers/advertise

Neurology ${ }^{\circledR}$ is the official journal of the American Academy of Neurology. Published continuously since 1951, it is now a weekly with 48 issues per year. Copyright () 2018 American Academy of Neurology. All rights reserved. Print ISSN: 0028-3878. Online ISSN: 1526-632X.

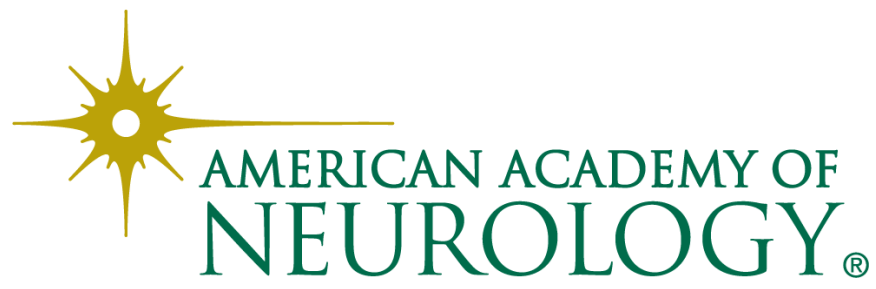

